\title{
Teaching Design and Practice of Operations Research Course in Mathematical Modeling and Mathematical Experiment
}

\author{
Zhuoshi Li ${ }^{\text {a }}$, Xiaoxu Chen ${ }^{\text {* }}$, Na Wang ${ }^{c}$ and Yu Zhang ${ }^{d}$ \\ Jilin Agricultural University, Changchun, Jilin,130118, China \\ aleezs643@sina.com, blzs036@163.com,,499360221@qq.com,
}

Keywords: operations research; mathematical modeling; educational design

\begin{abstract}
Combined with the characteristics of students and the current problems and shortcomings in the course of operational research, to the mathematical modeling and mathematical experiments for the two aspects of research, operational research course content, teaching mode, extracurricular practice appropriate reform, Learning the basic theory at the same time, pay attention to the specific issues to establish an effective mathematical model, through mathematical experiments to enhance the learning and use of mathematical optimization software, and achieved good results.
\end{abstract}

\section{Introduction}

Operations research is a newly developed discipline, the scope of the study is very extensive, in many areas of modern has an important application value [1]. Operations research courses in the colleges and universities of science, engineering, management and other professions are set up operations research courses. Operational research is a research-related issues of optimization disciplines, with mathematics as the main research tools, focusing on theory and practice. With multi-disciplinary and other characteristics. But in the traditional operation of the teaching process often pay more attention to the theory of teaching and ignore the importance of practical teaching, teaching content also exists monotonous, single form, students learning enthusiasm is not high, the face of specific practical problems to solve the problem is not strong and so on. Therefore, the operational research curriculum content, teaching model and other appropriate need reforming.

In the practice of teaching, we find that if we integrate the ideas and methods of mathematical modeling in the process of operational research, students will study the characteristics and internal laws of the actual problems by investigating and collecting the relevant model data, so as to grasp the key of the problem[2]. A certain set of assumptions, to establish a quantitative relationship between the number of practical problems, and finally the use of mathematical methods and techniques to analyze the number of relationships in the modeling process to develop their own research theory and related knowledge of learning interest. Students use the relevant theories and expertise of the maths learned by the university to arrange and guide the students to use MATLAB, Mathematic or Lingo and other related mathematical software in the experimental classroom to actively solve the mathematical model results, The practical application of some of the courses in the course of the study, the ability of students to use mathematical knowledge and computer to solve practical problems, to strengthen the students' hands-on ability, but also to cultivate students' interest in learning and to change some traditions of students' lectures learning method.

Through the combination of mathematical modeling and experimentation and operational 
research teaching, we can cultivate students 'ability to solve practical problems by using the knowledge they have learned, and ensure that students have a solid theoretical basis and meet the requirements of the development of students' The teaching reform of the course not only enriches the teaching content of the research course, but also appears in the teaching and extracurricular practice in the production, life and scientific research. It is necessary to prepare the basic theory study, change the teaching form of the course, Modeling for the process, the computer as the carrier, the mathematical software as a tool, but also to a certain extent, improve the students' interest in learning, teaching effect is positive.

\section{The Application of Mathematical Modeling in the Teaching of Operations}

Mathematical modeling is the link between mathematics and practical problems and the necessary way, is the only way to apply mathematics. Mathematical modeling of ideas and methods in many related disciplines and applications occupy a critical position and role. We often say that if we can effectively grasp the practical problems in the mathematical model, also caught the key to the problem[3].

The National University Students Mathematical Contest, which was co-sponsored by the Higher Education Department of the Ministry of Education and the China Society for Industrial and Applied Mathematics, has been successfully for more than 20 years since 1992 and has become the largest disciplinary competition in China's universities. Successfully promoted the reform of mathematics teaching, created the largest and most successful over the years to promote mathematical modeling as the core of mathematics teaching reform practice, many students are using "three days of hard work, do not participate in three years of regret" Is an exaggeration to say, but it has expressed the students through the intense competition process, feel and personal experience. The topic of the mathematical modeling contest is often the popular problem of production and life that needs to be solved at present. It highlights the wide application of mathematics. The students participate in the mathematical modeling activities of these problems. In the kingdom of mathematics, we Can be free to travel, free Imagination, personally experience the charm of mathematics.

Mathematical modeling enhances students' sense of innovation. The flexibility of mathematical modeling is very large. There is no uniform standard model. We often give reference answers, which require students to carry out, including mathematics and economic management for a certain period of time, Engineering and computer and application software and other multi-disciplinary knowledge of learning, but also requires students to have a certain ability to analyze problems and creative ability to solve problems. For the same practical problem, students can choose different angles to think about the problem, the use of different mathematical methods to build the model, the students can also through the mathematical experiment classroom, will establish the model, using different mathematical software or programming language to solve Model, to promote students to write their own procedures, the mathematical model of the program reflects the characteristics of their own models, based on a reasonable optimization algorithm for the calculation steps, as long as the students put forward the hypothesis is reasonable, the establishment of the model integrity is better, make full use of their own Or the creative thinking of the team, can be used in mathematical language, the text can be expressed correctly, can be obtained in the mathematical experimental course model effective solution. Therefore, the mathematical modeling and mathematical experimental activities to exercise the students 'divergent thinking and creative thinking ability, and enhance the students' sense of innovation. 


\section{Teaching Design Reflects Mathematical Modeling}

Teaching design is a teacher to reflect the curriculum teaching ideas, often should be based on the professional students of their own special[4].Point to guide the completion of specific teaching tasks, to conduct a reasonable teaching organization. Reform the teaching methods of operational research courses, strengthen the students in the experimental part of mathematics, fully mobilize the students to learn the product by. According to the characteristics of the course, we use classroom teaching, on the machine experiments, including lectures and social practice and other teaching methods. In the teaching design, the teacher should first pay attention to the teaching case related to the modeling problem, set some interesting questions which are closely related to the daily life, fully reflect the practicality of the problem, reflect the mathematical modeling thought at the same time, the design is reasonable The case. For example, now more popular take-away delivery service, takeaway brother travel in various school dormitories, living area, between the various hotels, they are more hard. Can be based on a number of takeaway brother a few days specific route to establish an optimal mathematical model, so that they are the most efficient, is the consumer and their own interests to maximize. As well as school cafeteria and banks and other service window, can be fast and efficient service is now people concerned about the problem, you can guide students to use their own time to take a window to the data, the use of mathematical methods for modeling analysis, put forward rationalization proposals, To take such a teaching case, you can fully mobilize the enthusiasm of students to learn, so that students take the initiative to participate in the entire course of teaching process, truly self-learning.

In the classroom teaching, we have selected representative typical examples and cases in production practice and explained it, so that students can gradually grasp the way to deal with the problem with the operational research course, so that students recognize the practical work of the course in the future Sex. This not only stimulates students' interest in learning, but also improves teaching efficiency. Of course, multimedia courseware is only a tool and means of teaching, teachers with the best book to complete the proof of the theorem, part of the example of teaching.

\section{The Application of Multimedia Teaching}

However, with the development of computer software, the traditional curriculum system can not meet the needs of the education system, so it is necessary to reform the traditional curriculum system, teaching content. The use of multimedia teaching methods in the teaching of operational research, can effectively use multimedia teaching software, through the design of vivid image of the teaching examples to improve students' attention, to stimulate students interest in learning. Only learning interest can be improved in order to better understand this course, and through the extension of knowledge for students to learn some professional services. Make full use of modern teaching methods, so that teaching content becomes rich and colorful. For the application of multimedia teaching in the course of operational research, the teaching process is optimized and the teaching quality is improved. In order to adapt to the development of the times, as soon as possible to change the traditional teaching of theoretical knowledge and practice less practical situation, most teachers believe that multimedia teaching is a good teaching methods, in the future teaching process will use this teaching method.Only the combination of multimedia teaching methods and traditional blackboard teaching in order to get the best classroom teaching results. In addition, the teacher through the appropriate classroom questions, discussion, testing, homework and other flexible way to achieve between teachers and students, the interaction between students, active classroom atmosphere, improve teaching efficiency. 


\section{Conclusion}

The theory and method of operational research have a wide range of applications in the production and life. In teaching, we can not only pay attention to the explanation of mathematical theory and mathematical method, but also pay attention to the mathematical modeling and mathematical experiment into our teaching system, The courses and the real world of extensive contact, through the organization of a reasonable teaching process, so that students are willing to think, generate active learning enthusiasm.

\section{Acknowledgement}

2016 Jilin Agricultural University School-based special subject: Operations Research study teaching model research and practice (project number: 2016JXZX22)

\section{References}

[1] Yunquan Hu. Operations research foundation and application. Beijing: Higher Education Press,2008.

[2] Hengyu Zhang,Tingyong Deng,Shuang Zhao.Application of Mathematical Modeling Thought in the Teaching Reform of Operations Research. Journal of Tonghua Normal University.35(2014) 91-93.

[3] FaSheng Hu,Guizhen Liu.Teaching Reform and Practice of National Great Course Operations Research .Chinese university education.7(2006) 9-10.

[4] TongSen Zhan,Weijie Liu,Zhaochun Xu.Discussion on the Reform of the Course System of Operations Research. Journal of Mathematical Sciences. 23(2007)11-13. 